\title{
Medical hazards of a four-km fun run
}

\author{
H. Bethell MRCP, FRCGP, D. Jewell* MRCGP and P. Burke ${ }^{\dagger}$ MRCPI, MRCGP
}

Alton Health Centre, Alton, Hants, ${ }^{*}$ General Practice Unit, Department of Epidemiology and Public Health Medicine, University of Bristol, Bristol and 'St. Bartholomew's Medical Centre, Cowley Road, Oxford, UK

\begin{abstract}
An observational study was conducted of participants in a 4-km race with the object of identifying risk factors for a poor outcome. Sixteen individuals were identified who required medical assistance at the end of the race. Pulse and lying and standing blood pressure were measured and a brief history was taken. Compared with 92 controls, the subjects showed a greater orthostatic drop in systolic blood pressure and were more likely to have consumed alcohol in the preceding $24 \mathrm{~h}$.
\end{abstract}

Keywords: Fun run, blood pressure, alcohol consumption, virus infections

\section{Introduction}

Fun runs are not always the fun they should be. There have been many reports in the literature of complications from open races, usually where the distance is $10 \mathrm{~km}$ or more ${ }^{1-4}$. Shorter races have been thought to be safe, but personal observation at the Sunday Times National Fun Run $(4 \mathrm{~km})$ reveals that some of the finishers look far from well. There are several reasons why such an event might produce ill effects.

1. Some of the runners are extremely unfit and inadequately prepared. In particular, some may enter after consumption of alcohol or during minor illness which would prevent them from taking part in a longer race.

2. The distance is short enough to encourage maximal effort.

3. The event, despite its title, is highly competitive.

This study aimed to identify those factors which might put at risk competitors in this $4-\mathrm{km}$ fun run.

\section{Subjects and methods}

The Sunday Times National Fun Run takes place annually in Hyde Park on the last Sunday in September. Thirty thousand people enter in 26 ageand sex-specific races over $4 \mathrm{~km}$. The event studied was on 29 September 1985, a pleasant autumn day, the temperature rising from $14.2^{\circ} \mathrm{C}$ at $9 \mathrm{a}$.m. to $24.6^{\circ} \mathrm{C}$ by mid-afternoon. The sun shone from mid-morning and the humidity varied from $90 \%$ at 6 a.m. to $50 \%$ at

Address for correspondence: Dr H. Bethell, Alton Health Centre, Anstey Rd, Alton, Hants GU34 2QX, UK

(C) 1991 Butterworth-Heinemann Ltd

0306-3674/91/040181-02
3 p.m. The wind speed was light. The races started at 10 a.m. and finished at 3.30 p.m.

Invitations were sent to 210 randomly selected entrants, ten in each age and sex group between the ages of 30 and 69 years, and five of each sex over 70 years. They were asked to attend the medical tent shortly before the start of their race. They were questioned about past illness, drug therapy, recent virus infection, average weekly training, usual training speed, alcohol consumption over the previous $24 \mathrm{~h}$ and fluid consumption on the day. Immediately after they finished the race, heart rate and erect and supine blood pressure were recorded. Their speed was calculated from the results published later. For each competitor a speed index was calculated, i.e. the ratio between actual speed and speed in training.

The patients were those runners over the age of $\mathbf{3 0}$ years, taken from the entire field, who either collapsed before or at the finish, or who were excessively pale and staggering as they left the finishing funnel. Their heart rate and erect and supine blood pressures were measured. They were asked the same questions as the controls and their speed calculated later.

Between-group comparisons were done using Yates' modification of the $\chi^{2}$ test for categorical variables and multiple regression in the statistical package for social sciences - personal computer version (SPSS-PC) for non-categorical variables, with correction for age and sex.

\section{Results}

There were 16 patients, none of whom came from the control group. Two had collapsed just before the finish and 14 fulfilled the study criteria at the finish. Among the patients were 13 men and three women (mean age 42.9 years), while among the 92 controls the figures were 54 men and 38 women (mean age 46.8 years) $\left(\chi^{2}=2.06\right.$ for sex).

Four $(25 \%)$ of the patients and $10(11 \%)$ of the controls had suffered a virus infection during the preceding week $\left(\chi^{2}=1.32, n\right.$.s. $)$. Within each age and sex category there was a trend for virus infections to affect the older competitors more frequently $(P=$ 0.01).

Four $(25 \%)$ of the patients and seven $(8 \%)$ of the controls reported an alcohol consumption of six units or more during the preceding $24 \mathrm{~h}\left(\chi^{2}=2.81\right.$, $0.05<P<0.1)$. Within each group there was a trend 
for such an alcohol consumption to be reported more frequently by men and by younger competitors.

Taking high-risk patients to be those who had either consumed six or more units of alcohol, or had a preceding virus infection, the eight $(50 \%)$ in the patient group represented a significantly greater proportion than the $18(20 \%)$ among the controls $\left(\chi^{2}=5.34, P<0.05\right)$. No patient or control had both suffered a virus infection in the previous week and drunk six units or more of alcohol in the previous $24 \mathrm{~h}$.

There was no significant difference, either before or after correction for age and sex, between the patients and controls for mean(s.d.) fluid intake on the day (553(196) versus 530(59) ml), mean(s.d.) training distance (9.8(3.6) versus 13.2(2.2) miles per week) and finishing heart rate (143(7.7) versus 136.3(4.4) beats/ min). Both groups ran slower than their stated training speed (speed index 1.1(0.1) versus 1.0 (0.02)\%).

The 14 patients who were able to stand showed a $22 \%$ (confidence interval 6.2) fall in systolic pressure from lying to standing. The corresponding 90 controls showed a $5.1 \%$ (confidence interval 2.3) fall. The difference between the two groups in postural blood pressure fall is significant (after correction for age and sex, $P<0.001$ ).

\section{Discussion}

The study showed no significant differences between patients and controls in most of the pre-race characteristics studied. Though the method of ascertainment was different for the two groups, this was felt to be unlikely to mask a true difference.

The collapse in most of the patients in this study was caused by orthostatic hypotension. Some showed clear evidence of mild heat exhaustion (heat syncope $^{5}$ ) such as prolonged tachycardia, impaired cognition and excessive sweating. However, rectal thermometry was not practical in the public glare of the first-aid tent, so this was not demonstrated. Others were presumably victims of the exerciseinduced postural hypotension seen in some apparently healthy subjects ${ }^{6,7}$.

Most of the risk factors for heat exhaustion or collapse in longer fun runs were not present in the patients in this study. The day was neither hot nor humid $^{8}$. There was no significant difference between the two groups for previous training, nor for fluid intake on the day $2-4,9,10$. Drugs did not seem to be a factor, and the patients did not run faster than they were used to doing. However, both excessive alcohol consumption and very recent viral infection may have been important contributory factors. There must be other unidentified factors, perhaps constitutional, since so many controls also had these risks without showing a tendency to postural hypotension.

It is worth noting that only $44 \%$ of those invited to be controls actually appeared. Since, overall, only 21513 out of 30000 entrants $(72 \%)$ ran on the day, about $61 \%$ of eligible controls came. In practice, it is possible that those potential controls with a recent virus infection or excessive alcohol consumption selected themselves out, thus producing a bias towards low risk in this group.

There were 9161 finishers in the age groups studied and, extrapolating from the figure for the controls, over 600 of them had drunk the equivalent of a bottle of wine or more the evening before. It is fortunate that only $0.17 \%$ became mildly unwell, and it is a testament to the safety of a $4-\mathrm{km}$ fun run, despite such unwise behaviour.

\section{References}

1 Sutton J, Coleman MJ, Millar AP, Lazarus L, Russo P. The medical problems of mass participation in athletic competition. The 'City-to surf' race. Med J Aust 1972; 2: 127-33.

2 Roydhouse N, Karn H, Johnson L. 1978 'Round the bays' $11.92 \mathrm{~km}$ fun run for 25000 entrants. NZ J Sports Med 1978; 6: 4-10.

3 Beard MEJ, Hamer JW, Hamilton G, Maslowski AH. Joggers heat stroke. NZ Med J 1979; 89: 159-61.

4 Hughson RL, Green HJ, Houston ME, Thomson JA, MacLean DR, Sutton JR. Heat injuries in Canadian mass participation runs. Can Med Assoc J 1980; 122: 1141-4.

5 Knochel JP. Dog day siriasis. How to kill a football player. JAMA 1975; 233: 513-15.

6 Fleg JL, Lakatta EG. Prevalence and significance of post exercise hypotension in apparently healthy subjects. Am J Cardiol 1986; 57: 1380-4.

7 Dubach P, Froelicher VF, Klein J, Oakes D, Grover-McKay M, Friis R. Exercise-induced hypotension in a male population. Circulation 1988; 78: 1380-7.

8 Clowes GHA, O'Donnel TF. Current concepts. Heat stroke. $N$ Engl J Med 1974; 291: 564-7.

9 Sherwood BK, Strong WB. Heat stress in athletes. J Med Assoc $\mathrm{Ga}$ 1985; 74: 478-80.

10 Sutton JR, Bar-Or O. Thermal illness in fun running. Am Heart J 1980; 100: 778-81. 